\title{
Hydrodynamic analysis of a low head prototype Francis turbine for establishing an optimum operating regime using CFD
}

\author{
G. Tiwari ${ }^{*}$, V. Prasad ${ }^{2}$, S.N. Shukla ${ }^{3}$ and V.K. Patel ${ }^{1}$ \\ 1 Department of Applied Mechanics, MNNIT Allahabad, Prayagraj, 211004, India \\ Phone: +919793258887, +919479957497 \\ 2 Department of Civil Engineering, MANIT, Bhopal, 462003, India \\ ${ }^{3}$ Research and Development, Kirloskar Brothers Ltd., Pune, 411045, India
}

\begin{abstract}
Hydraulic turbines need to operate at regimes other than designed ones. Off-design functioning of these turbines yields an inefficient and uneconomical operation of hydro projects. Performance and energy losses at different possible operating conditions need to be evaluated before finalizing the design of water turbines for satisfactory operations. Moreover, hydraulic turbines are unique machines designed for unique set of operating conditions and cost a huge percentage of the overall cost of the project. This work is compiled with twofold objectives; derivation of complete performance characteristics of a $48 \mathrm{~m}$ head prototype Francis turbine in order to establish an optimum operating regime and, determination and analyses of head loss at different components of the turbine. Steady state flow simulations for four different load operations $(60 \%$, $80 \%, 100 \%$ and $120 \%$ ) have been carried out using computational fluid dynamics. It is found that the optimum regime of operation lies within the speed factor range of 0.412-0.48 along with discharge factor range of 0.27-0.329 and maximum efficiency is obtained as $90.64 \%$ at full load operation. Maximum head loss in critical components of the turbine such as runner and draft tube is found as $12.7 \%$ at speed factor of 0.568 and $26.31 \%$ at 0.202 speed factor respectively. Also, the maximum total head loss in all the components is found as $47.8 \%$ at $60 \%$ load and 0.609 speed factor. It is concluded that the functioning of the turbine at higher speed factors is more detrimental than that at lower speed factors. Requirement of performance improvement at off-design conditions (especially at $60 \%$ load operation) is also suggested in order to widen the range of optimum operating regime. Obtained computational results are validated with experimental results and a strong agreement is found between the two.
\end{abstract}

ARTICLE HISTORY

Revised: $24^{\text {th }}$ Oct 2019

Accepted: $6^{\text {th }}$ Nov 2019

\section{KEYWORDS}

Francis turbine;

Performance

characteristics;

head loss;

computational fluid

dynamics.

\section{INTRODUCTION}

There has been an exponential growth in consumption of electricity as it is directly contributing in the development of countries for past few decades [1,2]. Consequently, the conventional resources have been exhausting rapidly. Moreover, continuous escalation of energy cost has prompted researchers to take interest in renewable energy like hydro power [3]. As a clean and renewable energy, hydro power plays a crucial role in the world energy scenario [4] and contributes about $50 \%$ of the renewable energy sources [5]. In fact, hydropower has been evolved as the most important renewable energy source for low as well as high electricity production [6]. Thus, it is an important source of energy along with its distinct advantages [7] like elimination of cost of fuel and damage of environment from greenhouse gas emissions [8]. In the past decades, tremendous growth in the new and renewable energy sources has been realized which is expected to increase further in the future [9]. However, the stability of electric power network is at risk [10] because of the stochastic and intermittent nature of such energy sources (especially wind and photovoltaic energy).

In the present scenario, there are two modes of power generation: continual and intermittent by using respective sources. In this highly competent environment of electricity production, demand of intermittent power generation has been increasing [11]. Where other renewable energy sources like wind energy and solar power exhibit random nature in picking up and rejecting the load during intermittent power generation [12], hydropower has been proved the most reliable source $[13,14]$. Hydropower plays an important role due to its unmatchable operating flexibility and capability of primary and secondary grid control by maintaining a balance between power generation and consumption $[15,16]$. However, this makes the hydro units run at off design conditions. Moreover, as the available flow rate is not constant throughout the year (low flow rates during the summer and high flow rates during the rainy seasons that too sometimes limited due to high sediment flow), it becomes practically impossible to run a hydro unit at BEP all the time [17]. Off-design regime of operation can be steady state or transient state [18]. At steady state regimes of operations, turbines are operated at constant values of head, discharge and speed and forces acted during these operations are also constant in magnitude, direction and frequency. During transient state of operations (such as during start-ups, stops, synchronizing and load changing), 
forces are not constant but vary in magnitude, direction and frequency. Thus, hydraulic turbines are acted upon by various steady and unsteady forces during their off-design operations and their nature and possible causes must be studied well before finalizing the design of the turbine.

For meeting the power demands of remote and isolated regions [19], small hydro projects have become the most popular due to the availability of more sites of its capacity range in such locations and, without the need of deforestation and resettlement [20]. However, hydro units installed in such projects often need to run at off-design regimes inevitably.

Hydraulic turbine is one of the key constituents of any hydro power project [21] as these are the prime movers used to convert the energy stored within the water into mechanical energy and subsequently into electricity through the use of a generator [1,22]. Due to their inherent structural characteristics [11], Francis turbines are the most widely used hydraulic turbines [23,24] for wide range of head applications [25]. In order to achieve the most economical functioning of hydro projects, efficiency of the turbine must be maintained higher. Performance of a hydraulic turbine is directly influenced by the regime of operation at hydro power plant $[1,26]$. The operating regime depends on the load demands at electric grid. Thus, the variation of efficiency with power output is the most important characteristics. In order to realize the changes in power output at off-design conditions, quantity of water to be admitted in the turbine is regulated using guide vane mechanism [27] and thus a constant synchronous speed is maintained. This changes the operating regime of the turbine other than the best efficiency point (BEP) to part load or full load (in case, if BEP is not at $100 \%$ load) or overload operations depending on the demand at the grid [28].

At off-design operations of Francis turbines, almost $60 \%$ of the total installed capacity is hindered because of disturbed complex flow structures through the machine depending on the operating conditions [5]. Part load operation of Francis turbine gives rise to undesired phenomenon like pressure pulsations due to precessing vortex rope generated at the exit of runner and significant pressure drop at inlet to the runner [29]. Whereas, full and overload regimes of operation of Francis turbines where discharge values are higher than that at BEP, may lead the turbine to an unstable and self-exciting condition [16]. Francis turbines at higher heads realize 2 to $5 \%$ drop in efficiency from design point whereas for lower heads around $15 \%$ drop can be observed [30].

In order to extract the maximum possible energy from any hydro project sites, it becomes essentially important to design hydraulic turbines for the site specific conditions [31]. This makes the hydraulic turbines to be unique machines that are designed for unique set of conditions [32]. Thus, designer must know the operating conditions at which the hydro turbines are expected to operate and their performance at those regimes of operation in advance so that the necessary design modifications for obtaining a wide optimum operating range can be done during the design cycle. This is also the motivation of the present work.

At the development stage (or during the rejuvenation of the existing turbine), a complete performance characteristic along with various losses at different components of the turbine space must be evaluated for ensuring an optimum design yielding an optimum performance. CFD is a robust and effective technique for derivation and evaluation of hydraulic turbines' performance characteristics through the facility of detailed flow field analysis [33]. Present work is solely dedicated to the derivation of complete performance characteristics of a low head 3 MW capacity prototype Francis turbine for establishing a range of optimum operating regime and a thorough analysis of head loss in different components of the turbine using CFD code ANSYS CFX.

\section{TURBINE GEOMETRY SPECIFICATIONS AND MESH STATISTICS}

In this work, a low head $(48 \mathrm{~m})$ horizontal axis prototype Francis turbine of $3 \mathrm{MW}$ capacity and $600 \mathrm{rpm}$ rated speed is considered. Geometrical specification of the turbine is given below in Table 1. A grid independency test is carried out and an optimum grid size is obtained by considering feasibility of available computational resources and convergence rate. Mesh statistics of different domains have been compiled in Table 2.

Table 1. Different geometry specifications for 3MW capacity Francis turbine.

\begin{tabular}{c|cc}
\hline & Attribute & Detail \\
\hline 1 & Runner diameter & $1.02 \mathrm{~m}$ \\
2 & Number of runner blades & 13 \\
3 & Number of guide vanes & 18 \\
4 & Number of stay vanes & 18 \\
\hline
\end{tabular}


Table 2. Grid size details of different domains.

\begin{tabular}{c|cc}
\hline Domain & Nodes & Elements \\
\hline Draft Tube & 201,743 & $1,037,775$ \\
Runner & 868,565 & $4,219,707$ \\
Spiral Casing & 273,955 & $1,452,620$ \\
Stay Vanes & 195,772 & 955,067 \\
guide vanes & 175,997 & 866,305 \\
All Domains & $1,716,032$ & $8,531,474$ \\
\hline
\end{tabular}

Figure 1 shows the geometry of different components along with complete flow domain and runner mesh and Figure 2 represents the grid independence test.

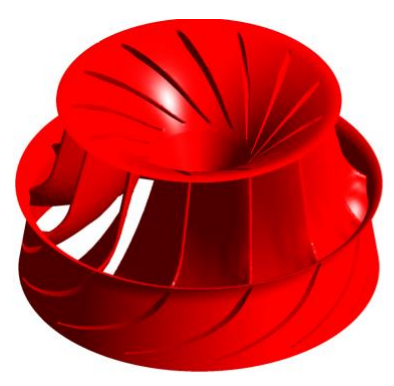

(a) runner geometry

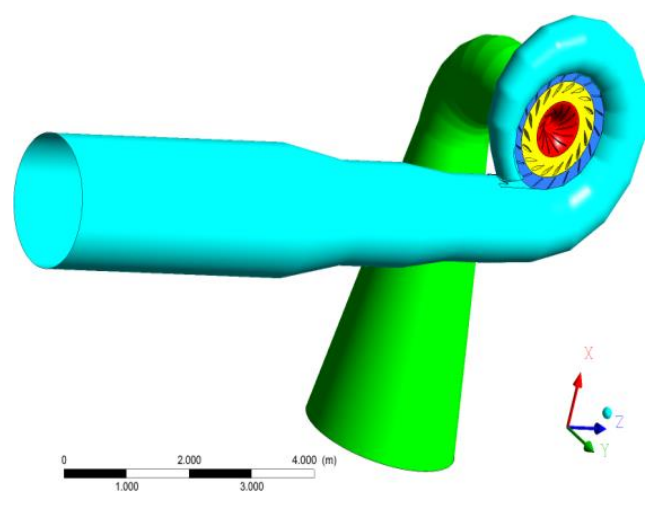

(c) whole assembly

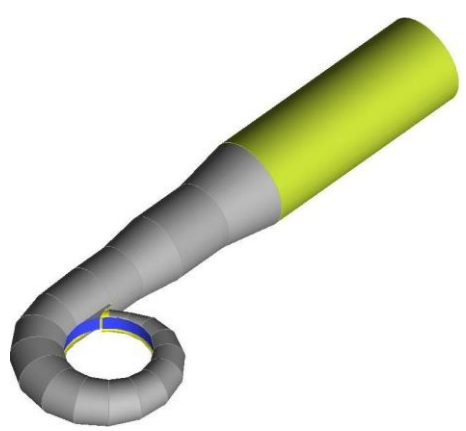

(b) spiral casing

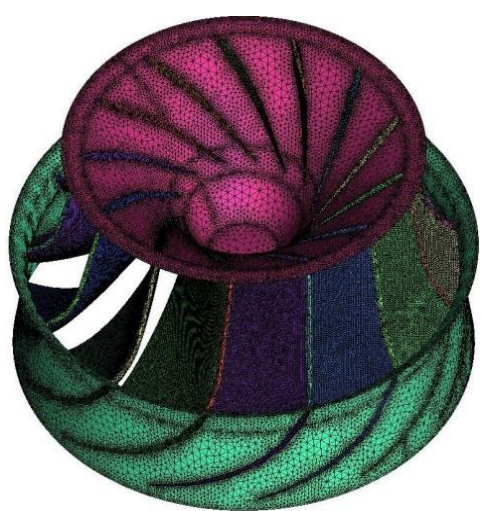

(d) runner mesh

Figure 1. Geometry of different components and runner mesh.

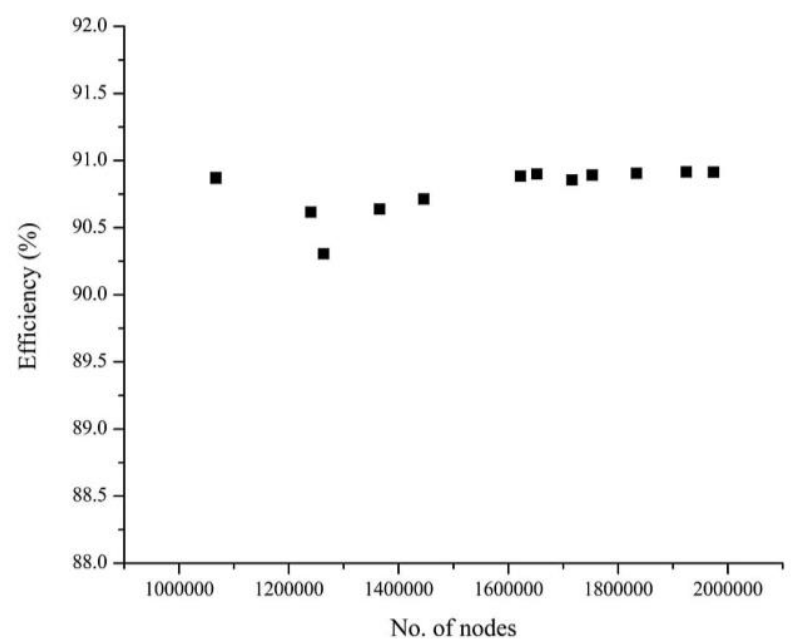

Figure 2. Grid independence test. 


\section{METHODOLOGY}

\section{Numerical Scheme and Boundary Conditions}

The computational domain consisting of runner, spiral casing, stay vanes, guide vanes and draft tube have been created and modified using Pro-E (Creo Parametric 5.0) and ICEM CFD (ANSYS 14.0). A high quality grid of different components enabling part meshing and prism layering at critical parts like runner blades is generated using ICEM CFD. In order to change the regime of operation, guide vane angle is varied corresponding to the flow rate at different loads. For approximating the effects of inherent fluctuation of head at hydro power site, rotational speed of the runner is varied at constant head. Separate domains have been created in CFX Pre from imported mesh of different components. Runner is set as rotating domain whereas other domains are kept stationary. These domains have been joined together with proper interfacing and different frame change options for different combinations of the domains. Interfacing between a stationary and a rotating domain is done using frozen rotor frame change option. Boundary conditions have been specified as mass flow inlet at spiral casing inlet and as static pressure outlet at draft tube outlet (Table 3 shows the boundary conditions used for the analyses). All the walls are taken smooth with no slip boundary condition. Reference pressure is taken as 0 atm in order to adopt the absolute scale for measurement of pressure. A comparative study amongst different turbulence models is carried out in order to make the most suitable choice according to the problem for taking turbulence effects into account. Figure 3 shows the comparison of different turbulence models with respect to the experimental results. Shear stress transport turbulence model with automatic wall function is found the most suited model and has been implemented for the whole analyses. Moreover, it is also suggested in literature that SST k-omega model is the best suited model for turbomachinery applications [34]. Advection scheme and turbulence numeric are set as high resolution each in solver control and Reynolds averaged Navier Stokes (RANS) equations along with the closure turbulent model equations have been solved for the numerical domain. Eqs. (1) and (2) show the governing equations to be solved at each node of the numerical domain.

$$
\begin{gathered}
\frac{\partial \rho}{\partial t}+\frac{\partial}{\partial x_{j}}\left(\rho U_{j}\right)=0 \\
\frac{\partial \rho U_{i}}{\partial t}+\frac{\partial}{\partial x_{j}}\left(\rho U_{i} U_{j}\right)=-\frac{\partial P^{\prime}}{\partial x_{i}}+\frac{\partial}{\partial x_{j}}\left[\mu_{e f f}\left(\frac{\partial U_{j}}{\partial x_{i}}+\frac{\partial U_{i}}{\partial x_{j}}\right)\right]+S_{M}
\end{gathered}
$$

where, $P^{\prime}$ is the modified pressure and $S_{M}$ is sum of all the body forces. The effective viscosity in the Eq. (2) is given by $\mu_{\text {eff }}=\mu+\mu_{t}$; where $\mu_{t}$ for SST k-omega turbulent model can be formulated [35] as given in Eq. (3).

$$
\mu_{t}=\rho \frac{a_{1} k}{\max \left(a_{1} \omega, S F\right)}
$$

where, $a_{l}$ is a constant, $k$ is turbulent kinetic energy, $\omega$ is dissipation rate of turbulent kinetic energy, $S$ is invariant strain rate and $F$ is a blending function which is an important element of shear stress transport model as it enables the switching from $k-\omega$ model (inside the boundary layer) to $k-\varepsilon$ model (outside the boundary layer).

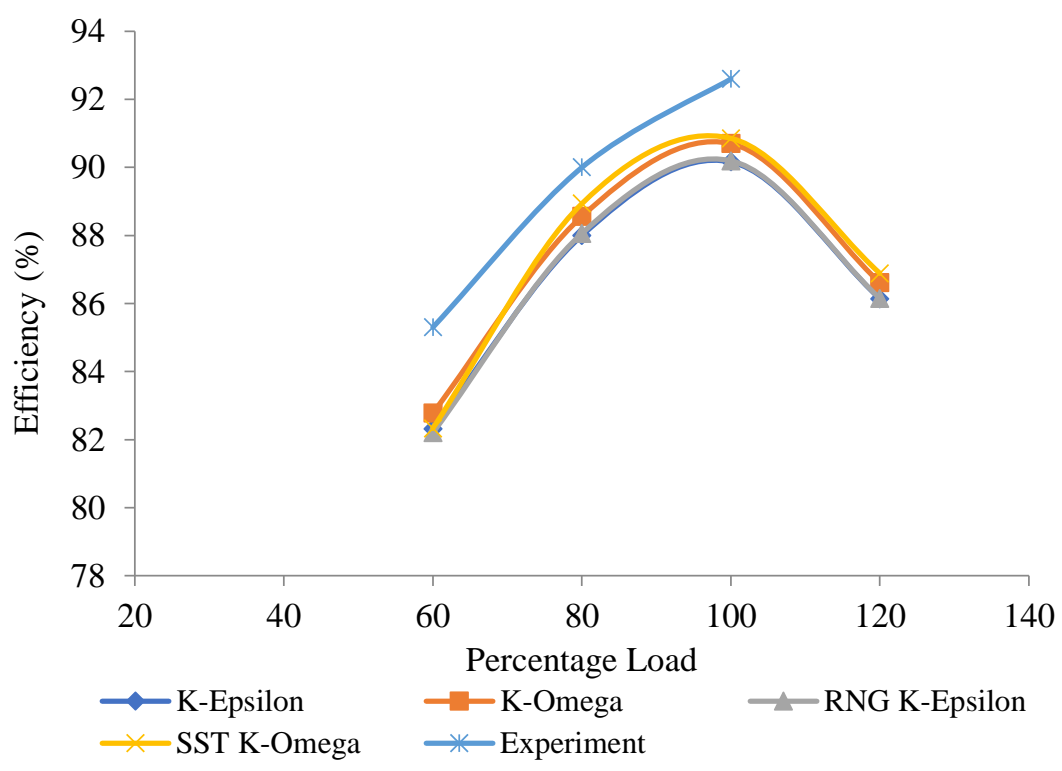

Figure 3. Comparison of different turbulent models for without cavitation case. 
Table 3. Boundary conditions and guide vane angles at different load operations.

\begin{tabular}{c|cccccc}
\hline & $\begin{array}{c}\text { Percentage } \\
\text { load }\end{array}$ & $\begin{array}{c}\text { GVO } \\
(\text { degree })\end{array}$ & $\begin{array}{c}\text { GVO } \\
(\mathrm{mm})\end{array}$ & $\begin{array}{c}\text { Mass flow rate at } \\
\text { casing inlet } \\
\left(\mathrm{m}^{3} / \mathrm{s}\right)\end{array}$ & $\begin{array}{c}\text { Static pressure at } \\
\text { draft tube outlet } \\
(\mathrm{atm})\end{array}$ & $\begin{array}{c}\text { Speed } \\
\text { range } \\
(\mathrm{rpm})\end{array}$ \\
\hline 1 & $60 \%$ & 16.227 & 52.99 & 4.71 & 1 & $400-800$ \\
2 & $80 \%$ & 20.431 & 66.723 & 5.93 & 1 & $400-800$ \\
3 & $100 \%$ & 24.800 & 81.01 & 7.20 & 1 & $400-800$ \\
4 & $120 \%$ & 31.145 & 101.715 & 9.04 & 1 & $400-800$ \\
\hline
\end{tabular}

\section{Different Quantities Utilized for Derivation of Performance Characteristics}

As the load demand on electric grid varies, synchronous speed of the hydraulic turbine tends to vary as well. Maintaining a constant speed with varying discharge in order to fulfill the load demands is one of the most important features of a hydraulic turbine. Thus, for obtaining performance characteristics of hydraulic turbines, variation of different derived quantities is seen with respect to different values of speed factor and discharge factor depending upon the operating conditions. The value of speed factor changes according to the change in head in actual conditions of any hydro project. However, for experimentation purposes (physical model testing or virtual CFD analysis), this change in speed factor is realized by changing the speed at constant value of head. Obtaining the ranges of speed factor and discharge factor is one of the major objectives of hydrodynamic design of water turbines in order to set the optimum operating regime [1]. For obtaining different characteristic curves, different quantities have been derived by using the expressions as shown in Table 4.

Table 4. Expressions utilized for deriving different quantities.

\begin{tabular}{cc}
\hline Quantity & Expression \\
\hline Net head & $H=\frac{T P_{1}-T P_{2}}{\rho g}$ \\
Head utilized by the runner & $H_{r}=\frac{P_{\text {out }}}{\gamma Q}$ \\
Input Power & $P_{\text {in }}=\rho g Q H$ \\
Output Power & $P_{\text {out }}=\frac{2 \pi N T}{60}$ \\
Efficiency & $\eta=\frac{P_{\text {out }}}{P_{\text {in }}} \times 100 \%$ \\
Speed Factor & $S_{f}=\frac{N D}{\sqrt{g H}}$ \\
Discharge Factor & $Q_{f}=\frac{Q}{D^{2} \sqrt{g H}}$ \\
Power factor & $P_{f}=\frac{P_{\text {out }}}{\rho D^{2}(g H)^{\frac{3}{2}}}$ \\
& $C_{p}=\frac{P-P_{2}}{\frac{1}{2} \rho W_{2}^{2}}$ \\
Coefficient of pressure &
\end{tabular}

\section{RESULTS AND DISCUSSIONS}

\section{Validation}

For establishing a reliability of the computational analyses, efficiency values for different load operations at rated speed i.e. at $600 \mathrm{rpm}$ are compared with the experimental values and a good accord between the two is found. Figure 4 shows the validation of computational results whereas Figure 5 indicates the comparison of the CFD and experimental results with showing the errors in simulation for different load operations at rated speed $600 \mathrm{rpm}$. It is clearly observed that the maximum simulation error (that is 3.06\%) occurs at $60 \%$ load operation. Experimental results for the prototype turbine have been provided by Kirloskar Brothers Ltd. Pune, India. 


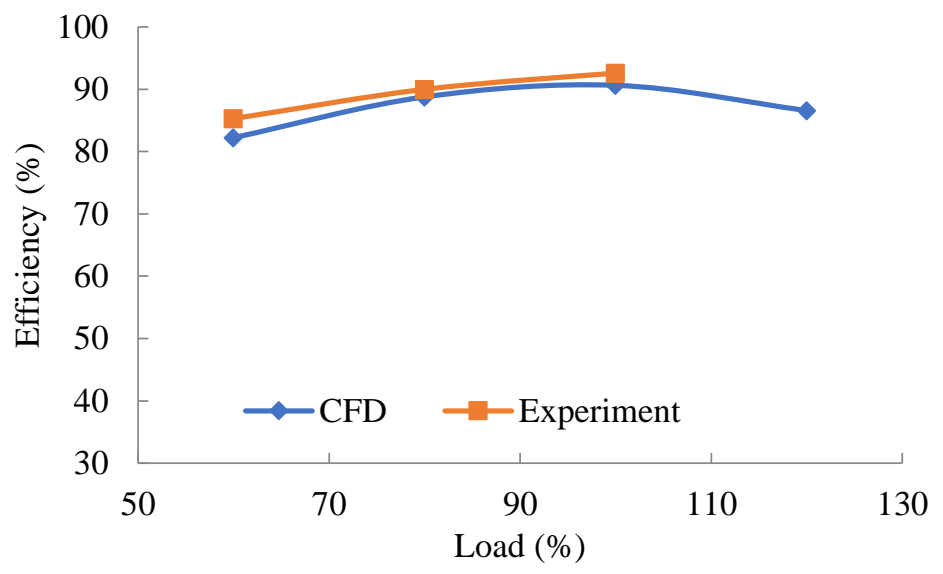

Figure 4. Validation of computational results.

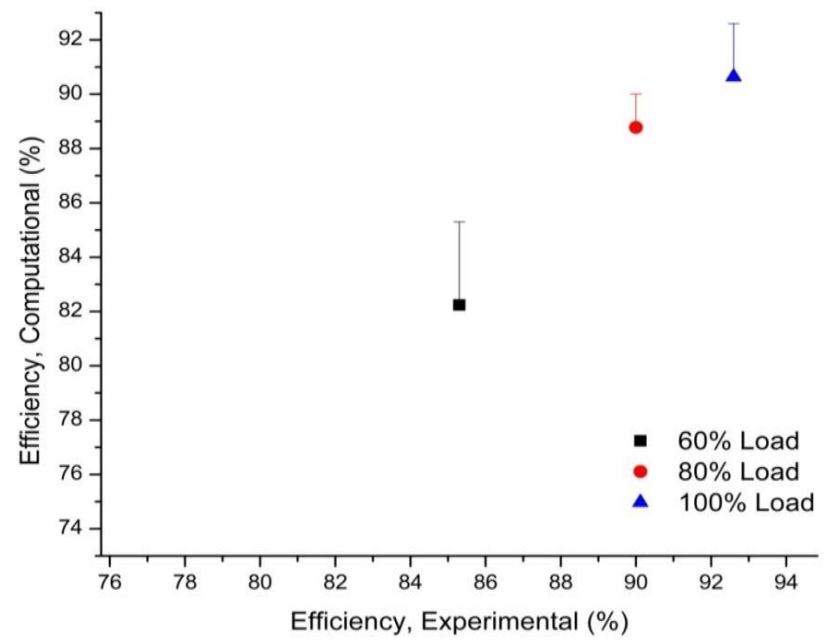

Figure 5. Comparison of Computational and experimental results.

\section{Performance Characteristics}

It is seen from the constant speed characteristics of the turbine as shown in Figure 6 that the design yields maximum efficiency of $90.64 \%$ while operating at full load. It is observed that as the operation of the turbine shifts from full load operation to either sides (part load and overload), there is a sharp decrease in efficiency. However, the part load operation of $80 \%$ manages to give satisfactory performance.

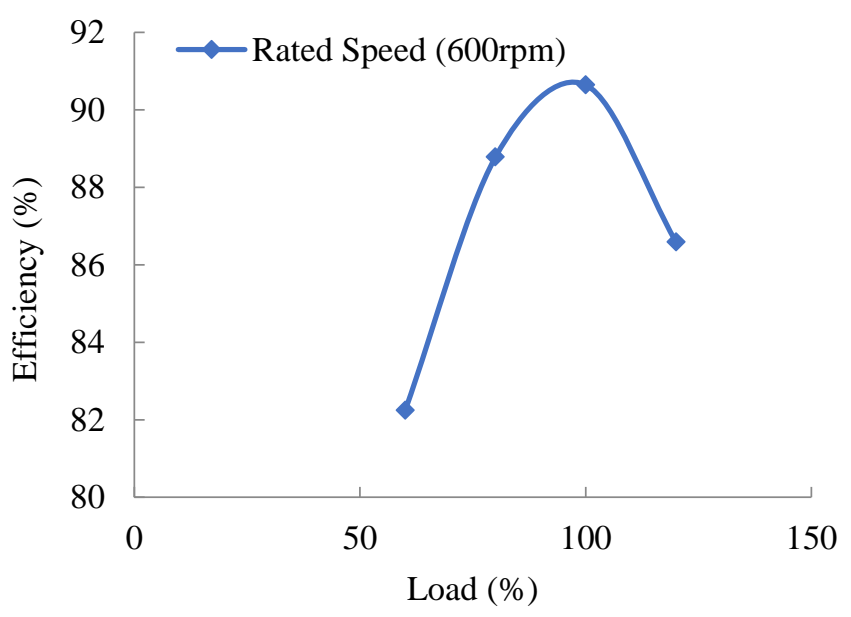

Figure 6. Constant speed characteristics of the turbine. 
Graph between speed factor and efficiency for different load opeations as dipicted in Figure 7 is showing that the maximum efficiency at any load operation is accomplished at a single value of speed factor as these curves are parabolic in nature. It is also noticed that at lower speed factors, difference in the efficiency values for different load operations is quite less whereas it is much significant for higher speed factors. It is due to the fact that at higher speed factors, losses in the turbine space are more (especially for off-design operations). It is also seen that the maximum efficiency shifts towards higher speed factor values for higher load operations. Again, it is clear from the figure that the full load (100\%) operation yields higher efficiency values than the other load operations i.e. part load and overload at different speed factors. Thus, the characteristic curves shift towards higher efficiencies as the load increases upto full load but as the load increases beyond $100 \%$, the curve shifts to lower efficiecy values.

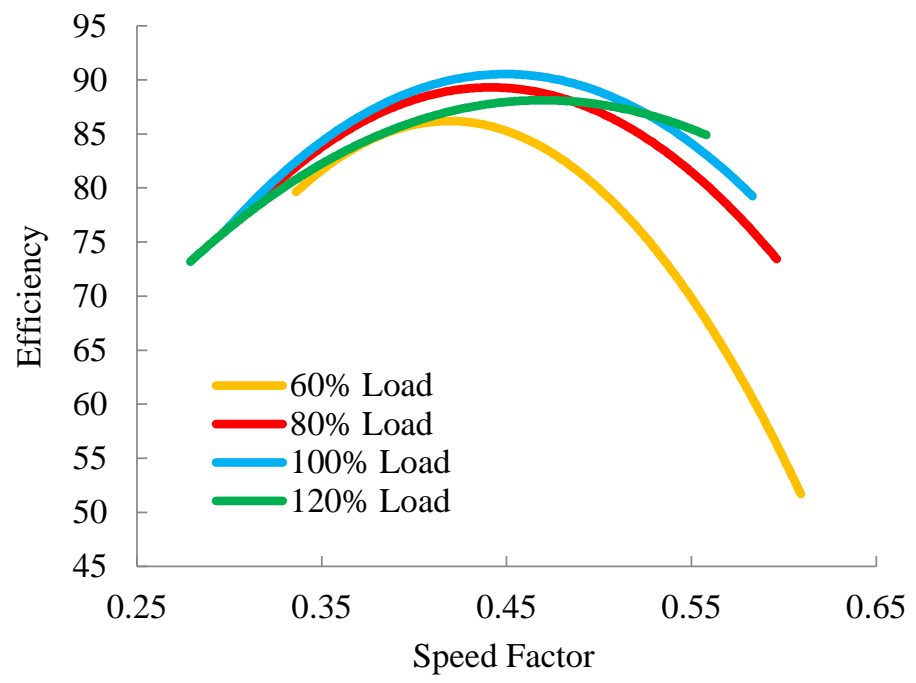

Figure 7. Speed factor versus efficiency curves (constant head characteristics).

Figure 8 deduces that power factor versus speed factor curves are parabolic in nature i.e. maximum power is attained at a single value of speed factor. For part load operations, the variation in power factor with speed factor is more. Part load operation of $60 \%$ realizes more decline in power at higher speed factors as head utilized by the runner for power production decreases dramatically at those ranges of speed factor (as shown in Figure 9). As the load increases, head available at the turbine and thus head utilized by the runner also increases. Head utilized by the runner depends upon the head available at the turbine and hydraulic losses in the runner. This is a possible explaination for the nature of curves in Figure 9.

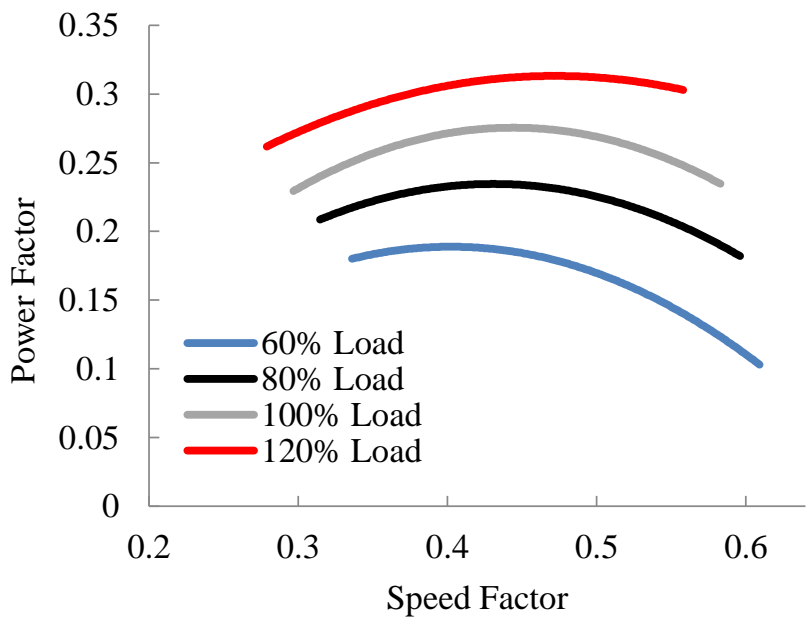

Figure 8. Variation in power factor with speed factor. 


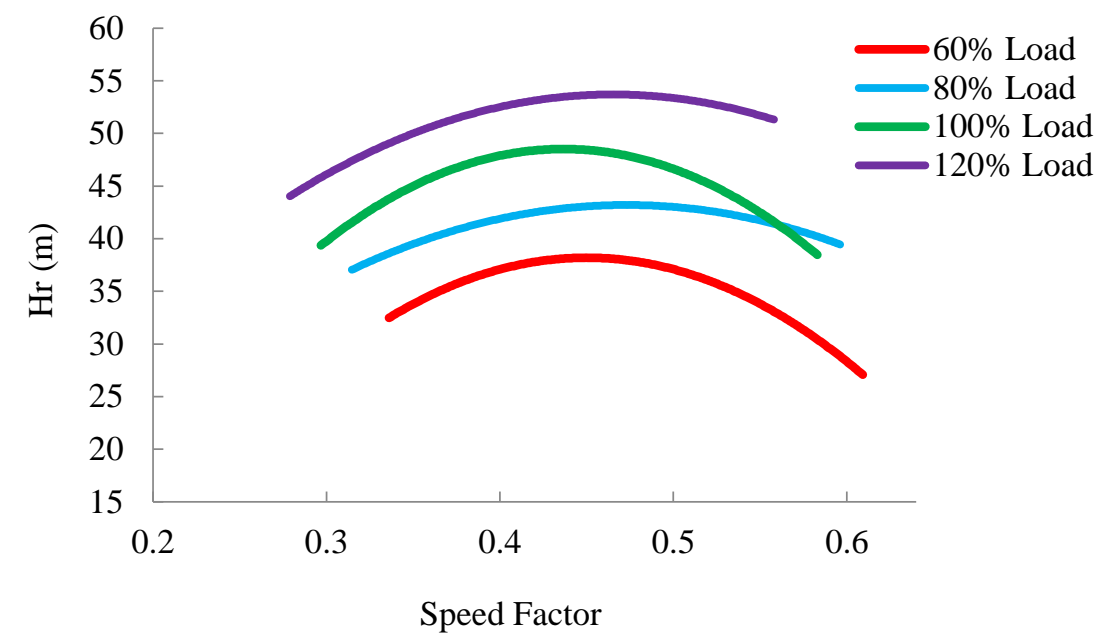

Figure 9. Variation of head utilized by the runner with speed factor.

Figure 10 shows that the discharge factor versus speed factor curves are drooping in nature for part load and full load operations whereas it is nearly straight line for overload operation. The nature of the curves suggests that discharge through the turbine gets disturbed at higher speeds as at higher speeds centrifugal force effects come into play. It is also observed that part load operations (especially $60 \%$ load regime) realize higher speed factors because of lower net heads available across the turbine at those regimes. It is due to the fact that head available across the turbine depends on the power demand on the grid and fluctuates accordingly.

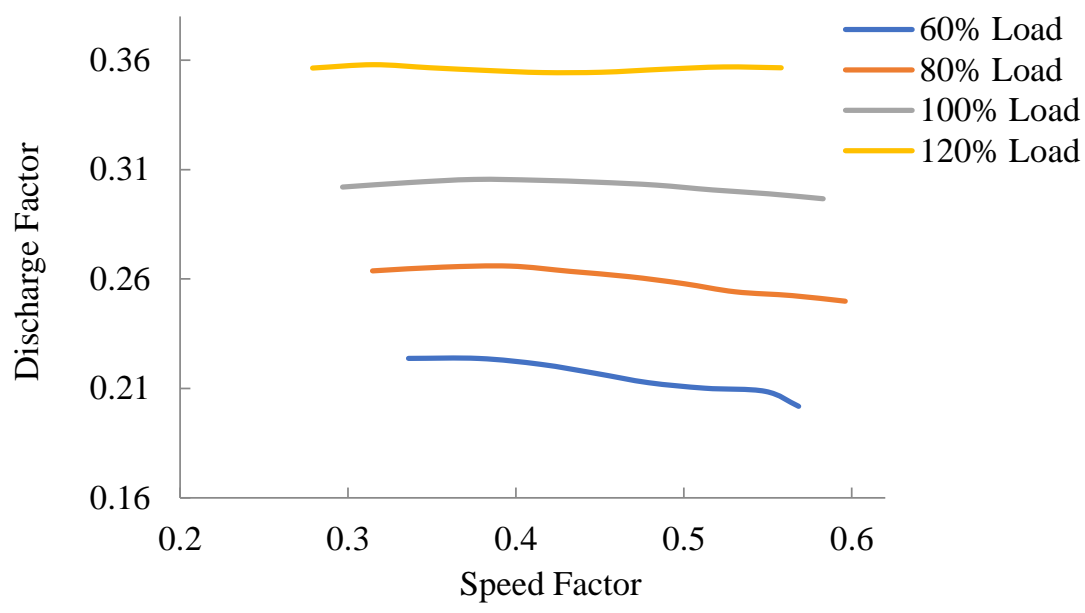

Figure 10. Discharge factor versus speed factor curves.

By utilizing the constant head characteristics and discharge factor versus speed factor characteristic curves, isoefficiency curves (hill chart) have been derived and shown in Figure 11. It is observed that efficiency decreases at either sides of the full load operation. With the help of hill chart, range of optimum operating regime in terms of speed factor and discharge factor has been derived as 0.412 to 0.48 and 0.27 to 0.329 respectively. 


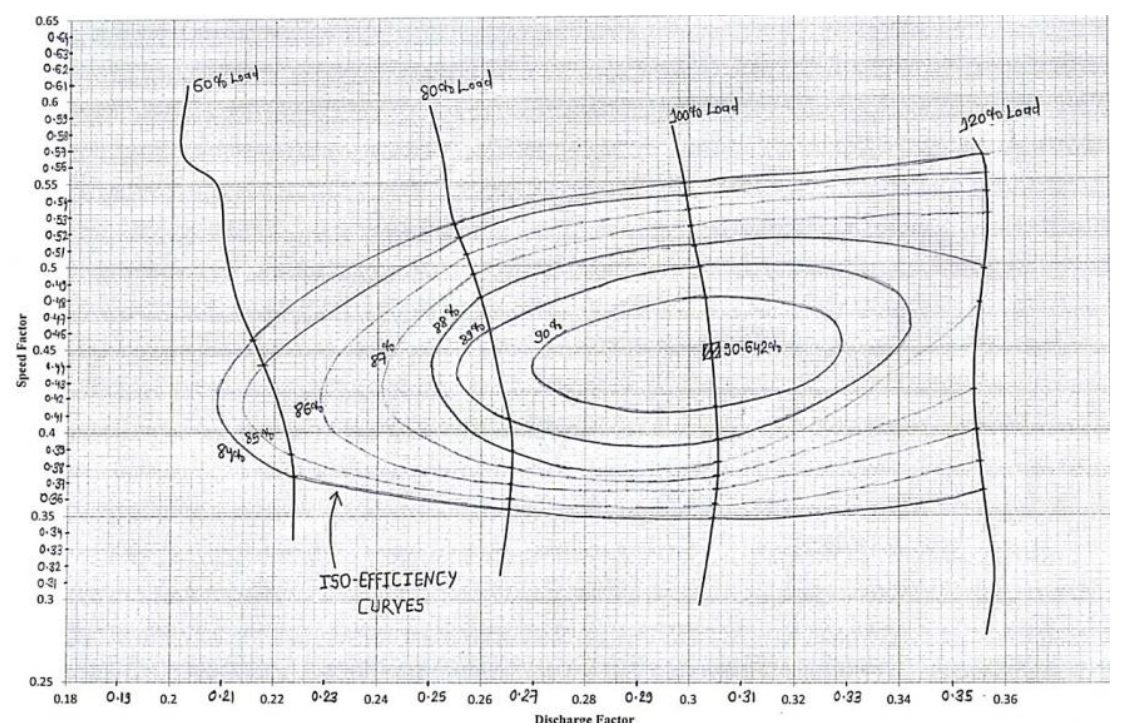

Figure 11. Iso-efficiency curves (hill chart) of the turbine.

\section{Analysis of Head Loss in Different Components of the Turbine}

For analyzing the effective functioning of different components, behavior of head losses in these components at different operating regimes are evaluated. Figure 12 represents the head loss in spiral casing, stay vanes, guide vanes, runner and draft tube at rated speed. It is found that head loss in spiral casing is very less $(<1 \%)$ for all the operating regimes considered in the analyses though it increases a bit as the discharge through the turbine increases. Likewise, in stay vanes, head loss increases as the discharge increases. It is evidently observed that the scope of energy loss is more around the runner as it is the component where energy transfer takes place. Therefore, the runner and upstream and downstream components to it that are guide vanes and draft tube respectively undergo higher energy losses. Head losses in guide vanes, runner and draft tube suggest that the part load operation of $60 \%$ is the most detrimental to the machine performance. In these components, head loss is found maximum at $60 \%$ load and minimum at full load operation. A detailed description about the nature of head loss in these individual components at different operating conditions is given in the subsequent discussions.

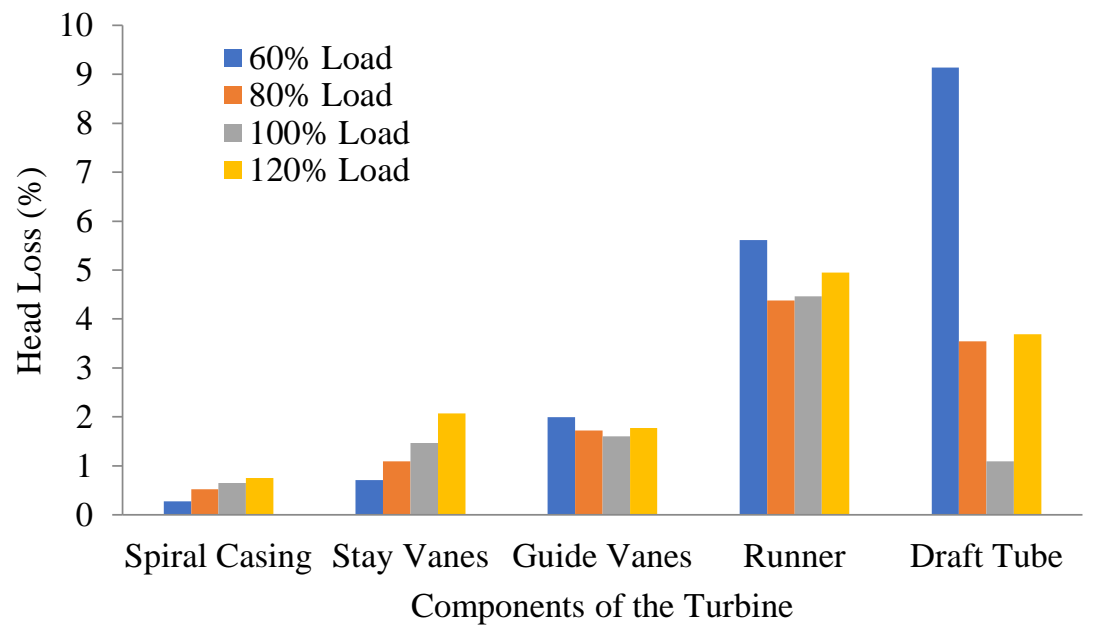

Figure 12. Head loss in different components at rated speed.

Figures 13 and 14 represent the head losses in spiral casing and stay vanes respectively for different load operations at different speeds. It is clearly seen that the head losses in these components are not significantly affected by speed but they vary reasonably with load demand. As the load increases, head loss in these components also increases. It is due to the fact that these are stationary components and their only hydrodynamic function is to distribute water properly towards the runner. Thus, as the flow rate through these components increases, kinetic energy loss due to higher flow velocities and consequently head loss in these components also increases. 


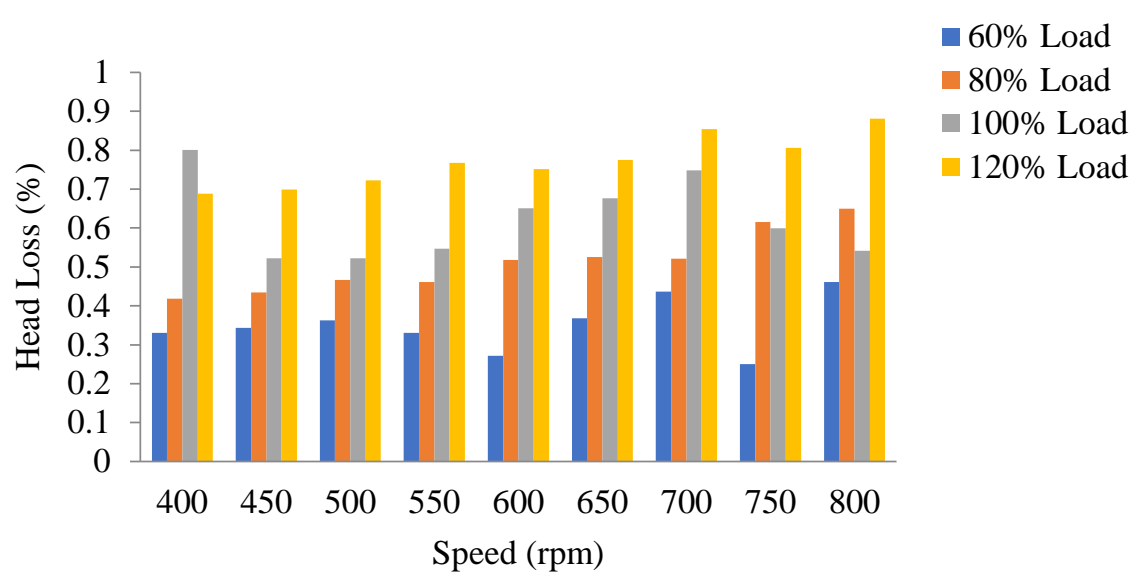

Figure 13. Head loss in spiral casing at different speed and load operations.

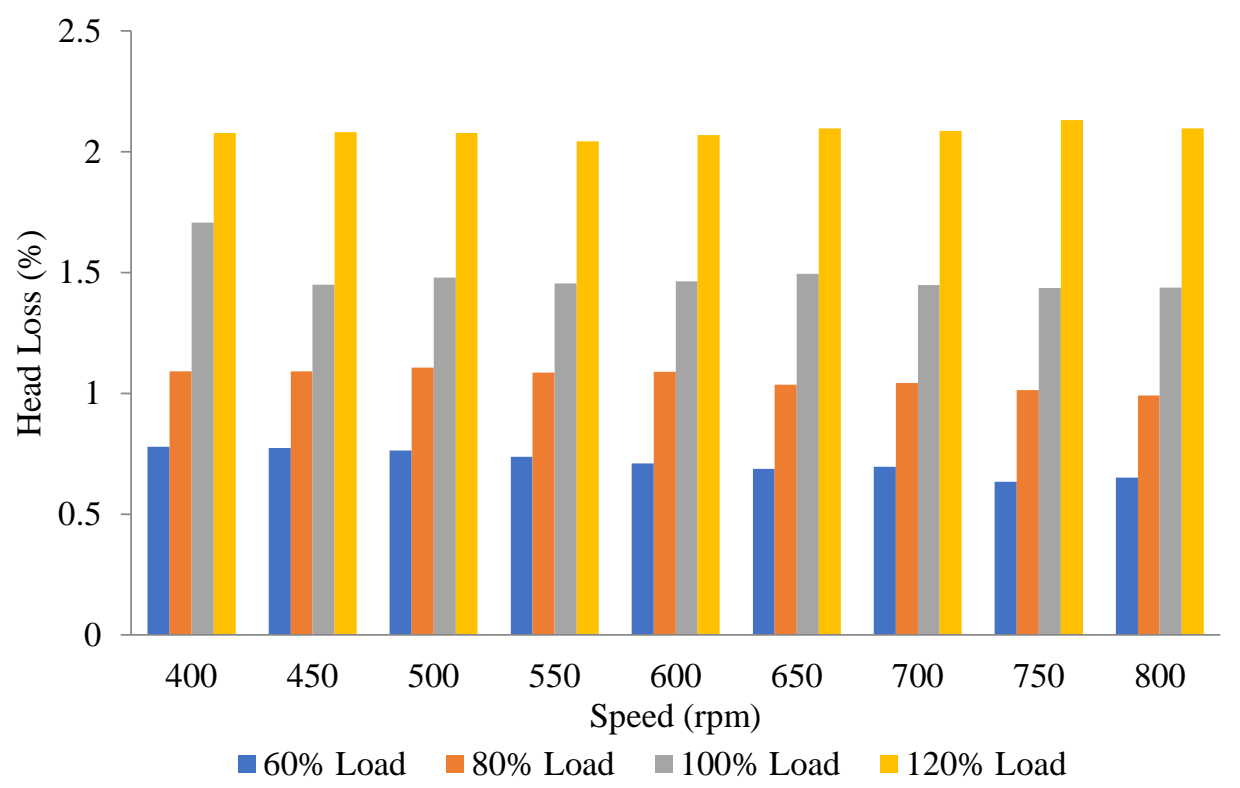

Figure 14. Head loss in stay vanes at different speed and load operations.

Head loss in guide vanes at different operating speeds and loads is shown in Figure 15. In guide vanes also, head loss does not vary considerably with speed but it varies between higher values and lower values for off-design and designed regimes of operation respectively. At off design regimes of operations i.e. at part load (especially at part load of 60\%) and overload, head losses are significantly greater as in these regimes of operations greater rotor- stator interaction effects comes into existence. It can be seen from Figure 16 that surface streamlines at mid plane of space between guide vanes and runner are showing high vorticity which is one of the soul reasons of strong rotor stator interaction effects. 


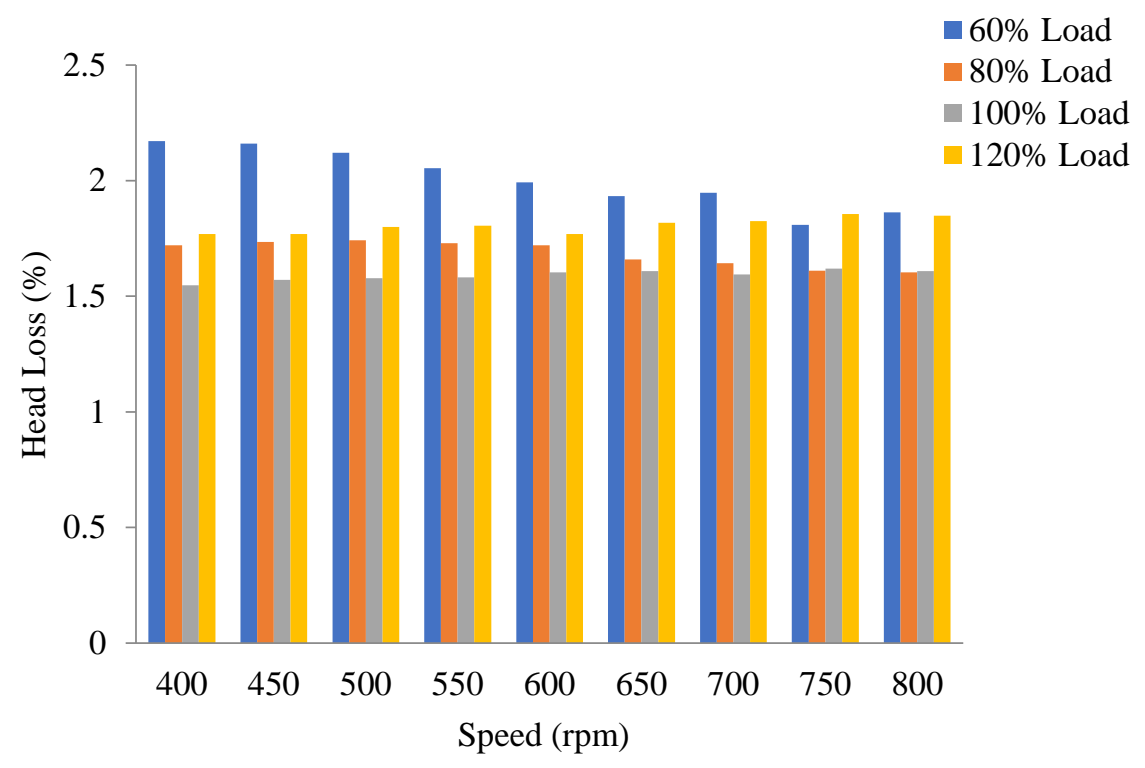

Figure 15. Head loss in guide vanes at different speed and load operations.
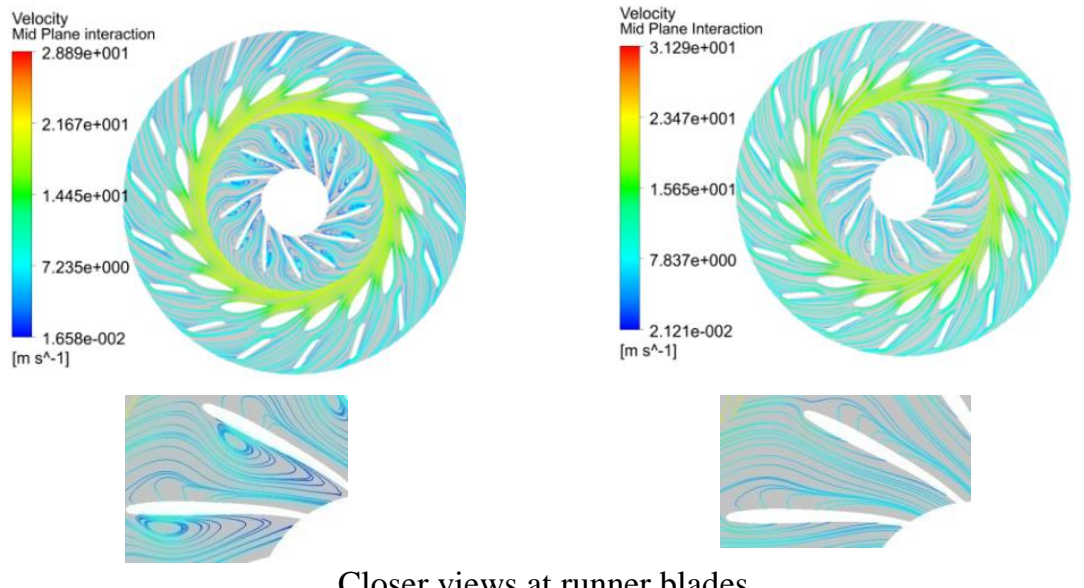

(a) $60 \%$ Load

Closer views at runner blades
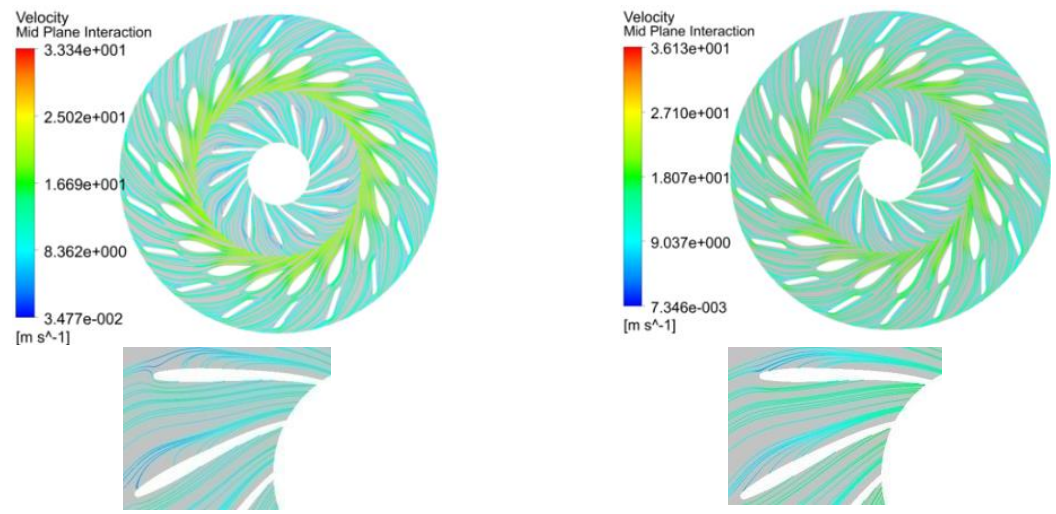

Closer views at runner blades

(c) $100 \%$ Load

(d) $120 \%$ Load

Figure 16. Surface streamlines at mid plane of stay vane, guide vane and runner for different load operations at rated speed $600 \mathrm{rpm}$.

Variation of head loss in runner as depicted in Figure 17 shows that it varies with load demand as well as speed. Head loss in runner is found minimum for full load operation at $650 \mathrm{rpm}$. It is evident from Figure 18 that during part load 
operations, entry of water at runner inlet is not smooth which gives rise to increased shock losses. Thus part load operations are detrimental to hydraulic stability of runner and cause more energy losses in the runner. However, full load operation realizes smooth entry of water in runner and incurs minimum energy losses. At the time of overload operation, water enters the runner quite smoother than that in case of part load operations. But increase in kinetic energy loss at exit of the runner due to increased flow rates, further contributes in head loss. As the speed increases, head loss in runner decreases up to the rated speed i.e. $600 \mathrm{rpm}$. Further increase in speed leads to increase in head loss, again too dramatically, for $60 \%$ load operation.

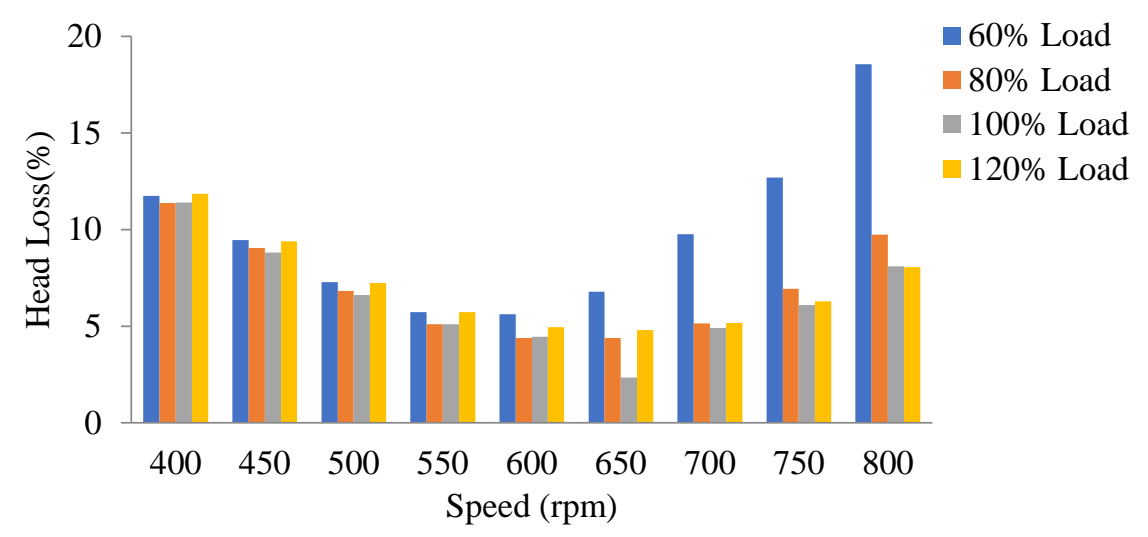

Figure 17. Head loss in runner at different speed and load operations.

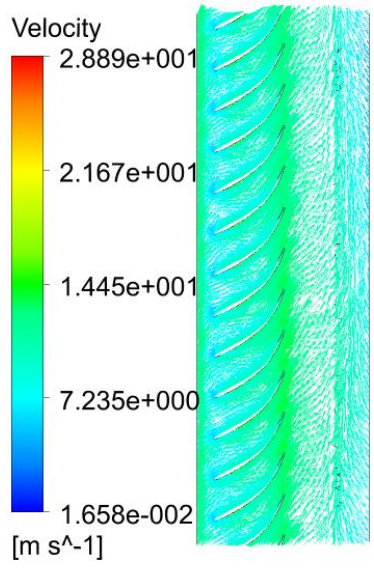

(a) $60 \%$ Load

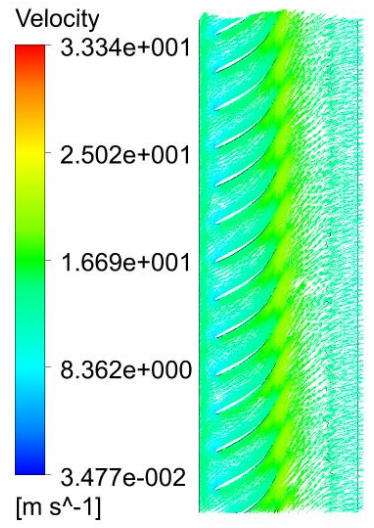

(c) $100 \%$ Load

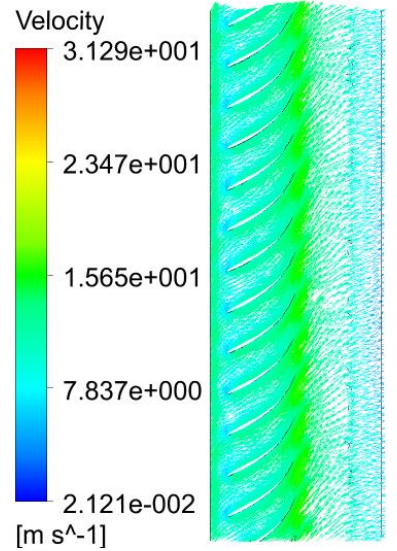

(b) $80 \%$ Load

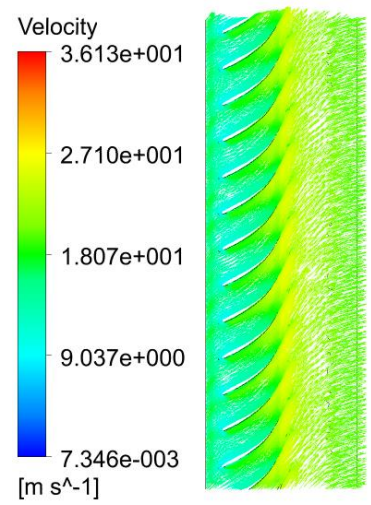

(d) $120 \%$ Load

Figure 18. Vector plot through runner cascade for different load operations at rated speed $600 \mathrm{rpm}$.

Head loss in draft tube is observed minimum at full load operation with rated speed as shown in Figure 19. The head loss decreases as speed increases up to the rated speed for part load of $80 \%$ and full load operations. For overload 
operation, head loss in draft tube is found decreasing with speed whereas it continuously increases with speed at part load of $60 \%$. At rated speed, part load of $60 \%$ operation results maximum head loss (around 9.5\%). High intensity swirl flow in draft tube is generated at $60 \%$ load (as depicted in Figure 20) which is one of the major reasons for more head loss in the draft tube. One of the primary causes for greater energy loss at $60 \%$ load is uneven pressure distribution on suction and pressure sides of the runner blades as shown in Figure 21.

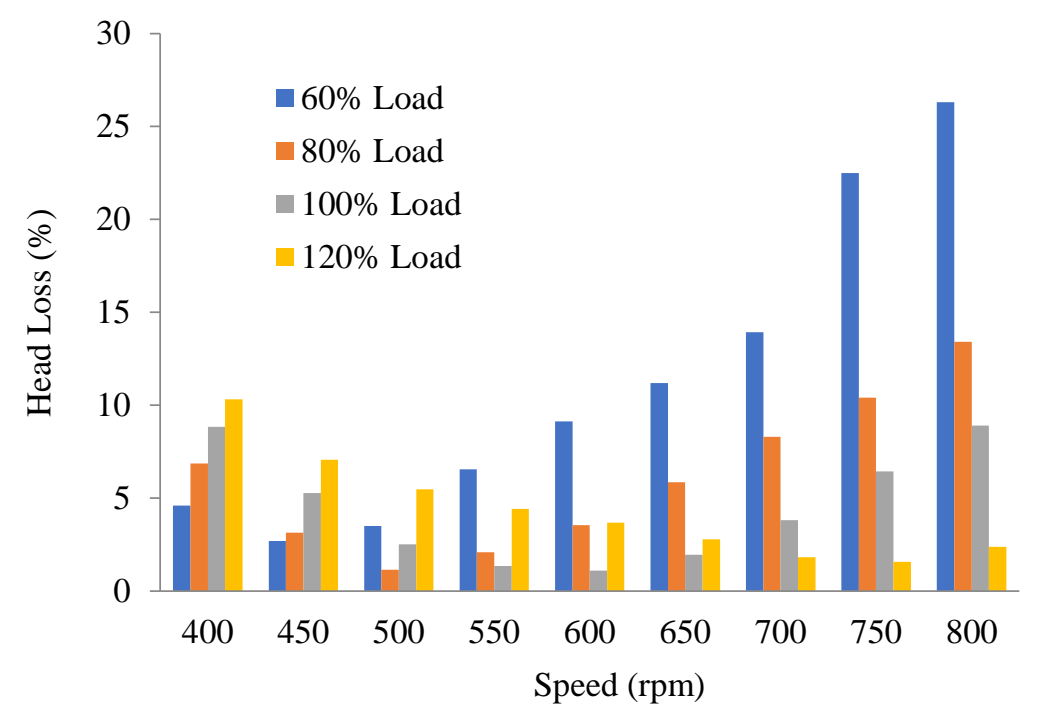

Figure 19. Head loss in draft tube at different operating speeds and loads.

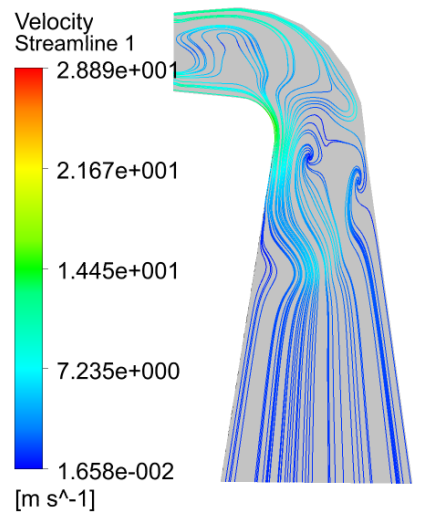

(a) $60 \%$ Load

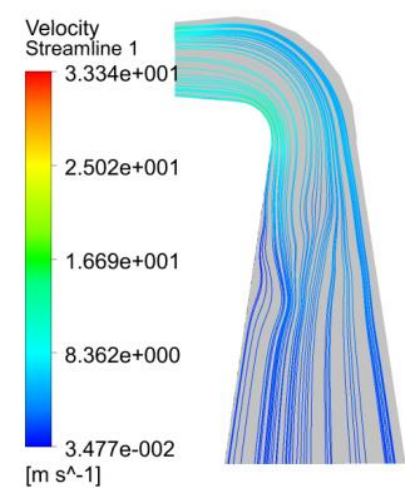

(c) $100 \%$ Load

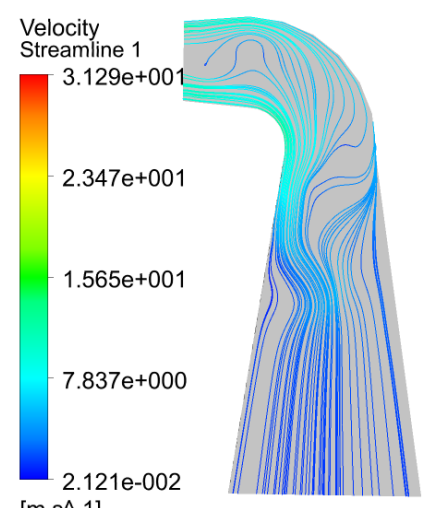

$\left[\mathrm{m} \mathrm{s}^{\wedge}-1\right]$

(b) $80 \%$ Load

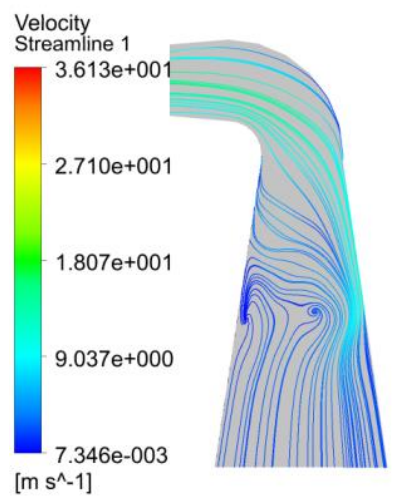

(d) $120 \%$ Load

Figure 20. Surface Streamlines on the mid-plane of draft tube for different load operations at rated speed $600 \mathrm{rpm}$. 


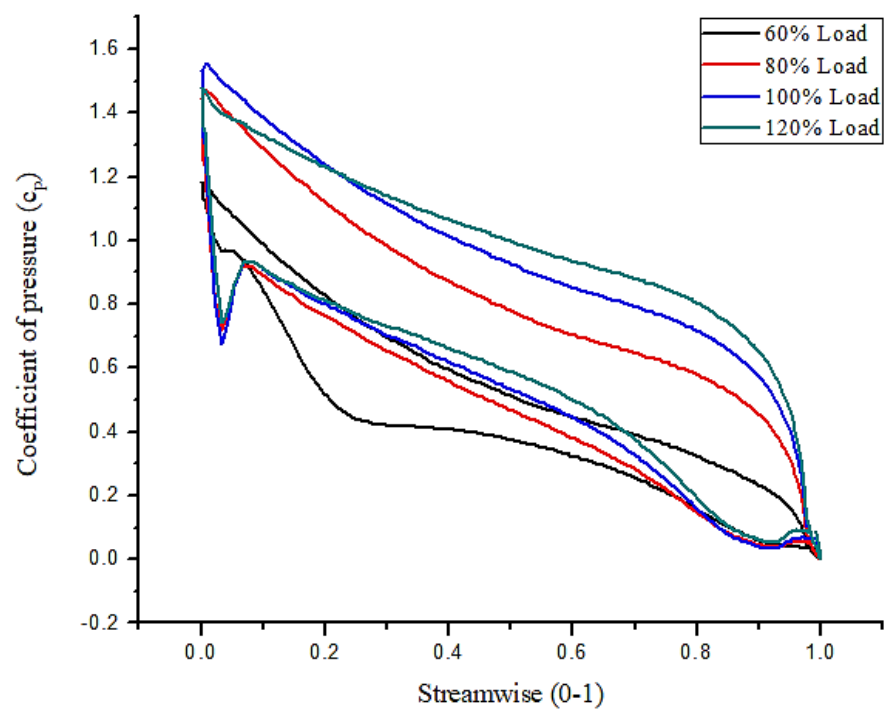

Figure 21. Distribution of pressure from leading to trailing edge of the runner blade at rated speed $600 \mathrm{rpm}$.

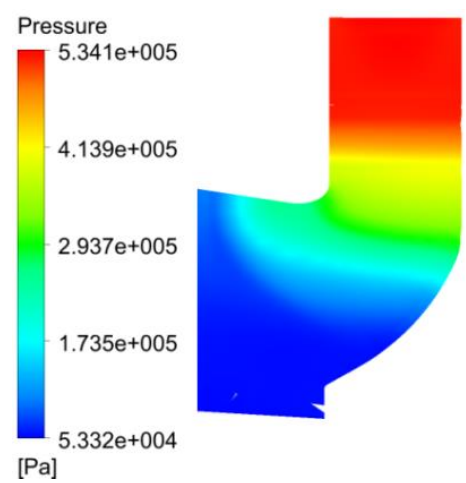

(a) $60 \%$ Load

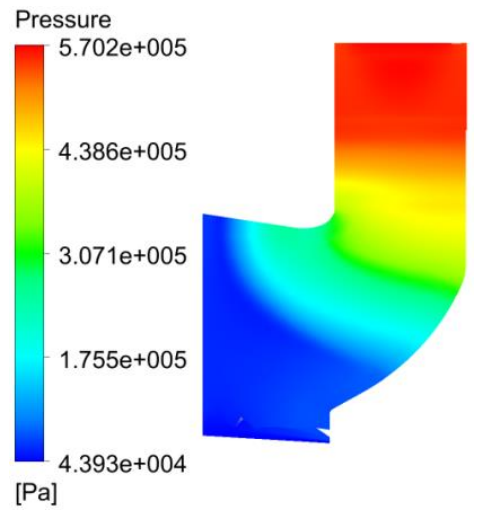

(c) $100 \%$ load

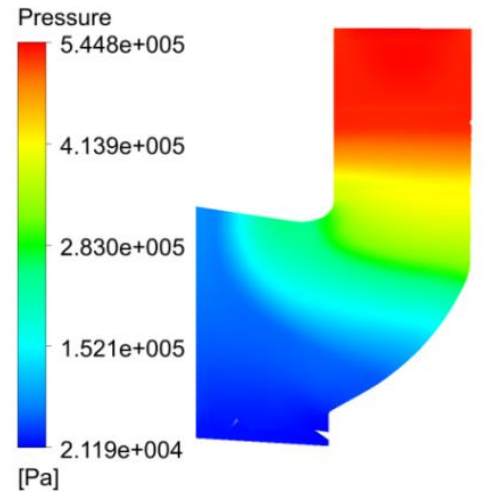

(b) $80 \%$ Load

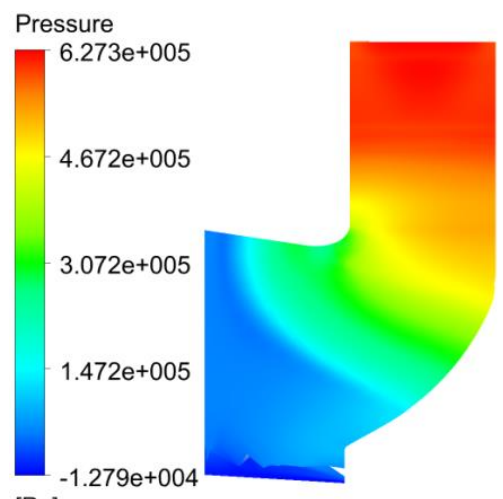

[Pa]

(d) $120 \%$ load

Figure 22. Distribution of pressure on meridional plane for different load operations at rated speed $600 \mathrm{rpm}$.

Figure 22 shows the change in pressure through the complete meridional plane from stay vane inlet to runner outlet at rated speed. It is seen for $60 \%$ load, pressure changes unevenly through runner passage. Thus, the conversion of energy is not smooth for this operation and most of the head goes waste in overcoming the losses.

Figure 23 represents the accumulative head loss in all the components for different load operations at different speeds. It suggests that the total head loss is maximum for part load operation of $60 \%$. It is also observed that in comparison to full load and overload operations, part load operations are more adversely affected by the increase in speed factor. It is due to the fact that for part load operations at higher speed factors, head loss in critical components like runner and draft tube increases drastically. It is seen that the total head loss is found minimum at speed factor range corresponding to the 
speed range of 600-650 rpm which lies in the optimum operating regime. It is also interesting to know that it is the range of speed factor in which head losses in runner and draft tube are found minimum at the operation corresponding to the best efficiency point that is the full load operation in the present case. This suggests the importance of critical hydrodynamic design of the runner and draft tube for obtaining an efficient performance of a hydraulic turbine.

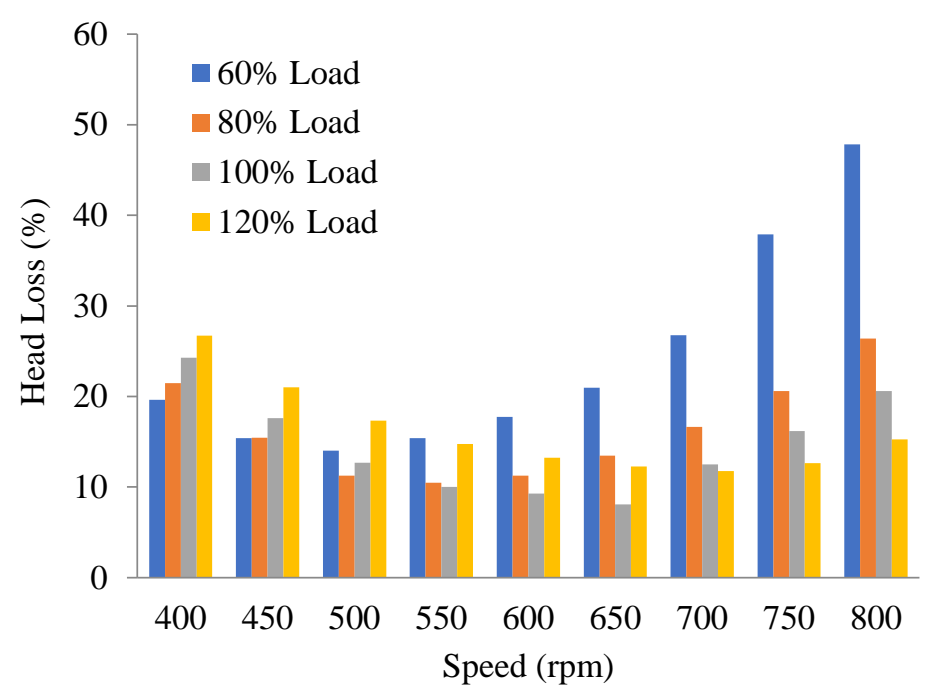

Figure 23. Total head loss at different speed and load operations.

\section{CONCLUSIONS}

In the work presented here, complete performance characteristics of a low head prototype Francis turbine has been derived. Based on the different performance curves, optimum operating regime of the turbine is obtained. Head losses in different components have also been calculated for different regimes of operation. The methodology adopted in CFD for deriving complete performance characteristics is found very effective. It yields the reasonable results in less time. Maximum efficiency of the turbine is $90.64 \%$ at full load operation. Thus, the best efficiency point is obtained as 0.448 speed factor and 0.304 discharge factor. The range of optimum operating regime is established in terms of speed factor as 0.412 to 0.48 and in terms of discharge factor as 0.27 to 0.329 . Head loss in runner is found minimum as $2.35 \%$ at full load (with speed factor- 0.4836 and discharge factor- 0.3029). Head loss in draft tube is found minimum as $1.069 \%$ at $100 \%$ load (with speed factor- 0.4484 and discharge factor- 0.3042 ). Total head loss is found minimum as $8.09 \%$ at $100 \%$ load (with speed factor- 0.4836 and discharge factor- 0.3029 ). It is found that, at higher speed factors, part load operations are much affected in comparison to full load and overload operations, and thus incur maximum losses in the turbine. Offdesign performance improvement of the turbine (especially at part load operation of 60\%) is one of the essential directions for future work. Detailed analysis of head loss in different components of the turbine indicates that the hydrodynamic design of runner and draft tube is the most critical for obtaining an efficient performance of the turbine. It is needed to evaluate various sources of energy loss such as processing vortex rope in the draft tube at part load operations in order to take necessary measures for performance improvement at those operating regimes. Evaluation of rotor-stator interaction effects is also suggested for minimizing head loss in guide vanes and runner domains.

\section{ACKNOWLEDGMENTS}

This work is carried out in collaboration with Kirloskar Brothers Ltd. Pune, India. No fund is received from any agency for execution of the work.

\section{REFERENCES}

[1] V. Barlit, "Hydraulic Turbines (Hydraulic Theory, Computations and Experimental Investigations), Vol-1, Vol-2," Maulana Azad National Institute of Technology, Bhopal, 2007.

[2] G. Tiwari, J. Kumar, V. Prasad, and V. K. Patel, "Derivation of cavitation characteristics of a 3MW prototype Francis turbine through numerical hydrodynamic analysis," Materials Today: Proceedings, 2020.

[3] C. Warnick, "Hydropower engineering," 1984.

[4] W. Wang, Q. Chen, D. Yan, and D. Geng, "A novel comprehensive evaluation method of the draft tube pressure pulsation of Francis turbine based on EEMD and information entropy," Mechanical Systems and Signal Processing, vol. 116, pp. 772-786, 2019. 
[5] S. Pasche, F. Gallaire, and F. Avellan, "Origin of the synchronous pressure fluctuations in the draft tube of Francis turbines operating at part load conditions," Journal of Fluids and Structures, vol. 86, pp. 13-33, 2019.

[6] T. M. Arispe, W. de Oliveira, and R. G. Ramirez, "Francis turbine draft tube parameterization and analysis of performance characteristics using CFD techniques," Renewable Energy, vol. 127, pp. 114-124, 2018.

[7] E. Septyaningrum et al., "Performance analysis of multi-row vertical axis hydrokinetic turbine-straight blade cascaded (VAHT-SBC) turbines array," Journal of Mechanical Engineering and Sciences, vol. 13, no. 3, pp. 5665-5688, 2019.

[8] G. Kahraman, H. L. Yücel, and Y. Taşgin, "Identification of optimum working conditions in hydroelectric power plants for cavitation," Engineering Failure Analysis, vol. 96, pp. 168-174, 2019.

[9] A. Favrel, J. G. P. Junior, C. Landry, A. Müller, K. Yamaishi, and F. Avellan, "Dynamic modal analysis during reduced scale model tests of hydraulic turbines for hydro-acoustic characterization of cavitation flows," Mechanical Systems and Signal Processing, vol. 117, pp. 81-96, 2019.

[10] S. Mauro, R. Lanzafame, S. Brusca, and M. Messina, "Unsteady computational fluid dynamics analysis of the hydrodynamic instabilities in a reversible Francis turbine used in a storage plant," Heliyon, vol. 5, no. 9, p. e02441, 2019.

[11] C. Trivedi, E. Agnalt, and O. G. Dahlhaug, "Experimental study of a Francis turbine under variable-speed and discharge conditions," Renewable Energy, vol. 119, pp. 447-458, 2018.

[12] D. Puspitasari and K. Sahim, "Effect of Savonius blade height on the performance of a hybrid Darrieus-Savonius wind turbine," Journal of Mechanical Engineering and Sciences, vol. 13, no. 4, pp. 5832-5847, 2019.

[13] P. Kumar and R. Saini, "Study of cavitation in hydro turbines-A review," Renewable and Sustainable Energy Reviews, vol. 14, no. 1, pp. 374-383, 2010.

[14] C. Trivedi, P. J. Gogstad, and O. G. Dahlhaug, "Investigation of the unsteady pressure pulsations in the prototype Francis turbines-Part 1: steady state operating conditions," Mechanical Systems and Signal Processing, vol. 108, pp. 188-202, 2018.

[15] R. Goyal and B. K. Gandhi, "Review of hydrodynamics instabilities in Francis turbine during off-design and transient operations," Renewable Energy, vol. 116, pp. 697-709, 2018.

[16] J. G. Pereira Jr et al., "Procedure for predicting part load resonance in Francis turbine hydropower units based on swirl number and local cavitation coefficient similitude," Mechanical Systems and Signal Processing, vol. 132, pp. 84-101, 2019.

[17] R. Aponte et al., "Minimizing erosive wear through a CFD multi-objective optimization methodology for different operating points of a Francis turbine," Renewable Energy, vol. 145, pp. 2217-2232, 2020.

[18] A. Luna-Ramírez, A. Campos-Amezcua, O. Dorantes-Gómez, Z. Mazur-Czerwiec, and R. Muñoz-Quezada, "Failure analysis of runner blades in a Francis hydraulic turbine-Case study," Engineering Failure Analysis, vol. 59, pp. 314-325, 2016.

[19] D. Ramirez, A. Rubio-Clemente, and E. Chica, "Design and numerical analysis of an efficient H-Darrieus vertical-axis hydrokinetic turbine," Journal of Mechanical Engineering and Sciences, vol. 13, no. 4, pp. 6036-6058, 2019.

[20] P. P. Gohil and R. Saini, "Effect of temperature, suction head and flow velocity on cavitation in a Francis turbine of small hydro power plant," Energy, vol. 93, pp. 613-624, 2015.

[21] G. Tiwari, V. Prasad, S. Shukla, and V. K. Patel, "Derivation of Complete Performance Characteristics of a Low Head Prototype Francis Turbine Using CFD," in Advances in Mechanical Engineering: Springer, 2020, pp. 1581-1591.

[22] G. Biswas, Introduction to Fluid Mechanics and Fluid Machines, 2e. Tata McGraw-Hill Education, 2003.

[23] S.-J. Kim, Y.-S. Choi, Y. Cho, J.-W. Choi, and J.-H. Kim, "Effect of blade thickness on the hydraulic performance of a Francis hydro turbine model," Renewable energy, vol. 134, pp. 807-817, 2019.

[24] D. Valentín, A. Presas, C. Valero, M. Egusquiza, E. Jou, and E. Egusquiza, "Influence of the hydrodynamic damping on the dynamic response of Francis turbine runners," Journal of Fluids and Structures, vol. 90, pp. 71-89, 2019.

[25] A. Presas, Y. Luo, Z. Wang, and B. Guo, "Fatigue life estimation of Francis turbines based on experimental strain measurements: Review of the actual data and future trends," Renewable and Sustainable Energy Reviews, vol. 102, pp. 96-110, 2019.

[26] P. Nag, Power plant engineering. Tata McGraw-Hill Education, 2002.

[27] B. H. Shanab, M. E. Elrefaie, and A. A. El-Badawy, "Active control of variable geometry Francis Turbine," Renewable Energy, vol. 145, pp. 1080-1090, 2020.

[28] M. Altimemy, B. Attiya, C. Daskiran, I.-H. Liu, and A. Oztekin, "Mitigation of flow-induced pressure fluctuations in a Francis turbine operating at the design and partial load regimes-LES simulations," International Journal of Heat and Fluid Flow, vol. 79 , p. $108444,2019$.

[29] A. Laouari and A. Ghenaiet, "Predicting unsteady behavior of a small francis turbine at several operating points," Renewable energy, vol. 133, pp. 712-724, 2019.

[30] X. Liu, Y. Luo, B. W. Karney, and W. Wang, "A selected literature review of efficiency improvements in hydraulic turbines," Renewable and Sustainable Energy Reviews, vol. 51, pp. 18-28, 2015.

[31] K. Celebioglu, B. Altintas, S. Aradag, and Y. Tascioglu, "Numerical research of cavitation on Francis turbine runners," International Journal of Hydrogen Energy, vol. 42, no. 28, pp. 17771-17781, 2017.

[32] J. G. Pereira Jr, L. Andolfatto, and F. Avellan, "Monitoring a Francis turbine operating conditions," Flow Measurement and Instrumentation, vol. 63, pp. 37-46, 2018.

[33] W. Hakim Safi and V. Prasad, "Design and Permance Analysis of Francis Turbine for Hydro Power Station on Kunar River Using CFD," International Journal of Advanced Research, vol. 5, pp. 1004-1012, 05/31 2017. 
[34] H. Zhang and L. Zhang, "Numerical simulation of cavitating turbulent flow in a high head Francis turbine at part load operation with OpenFOAM," Procedia Engineering, vol. 31, pp. 156-165, 2012.

[35] C. ANSYS, "16.0," ANSYS CFX Tutorials, 2015. 